\title{
MAIORIDADE PENAL, OS 25 ANOS DO ECA E O DIREITO FINANCEIRO
}

Coluna publicada em 28.7.2015: <http://www.conjur.com.br/2015-jul-28/ contas-vista-maioridade-penal-25-anos-eca-direito-financeiro $>$

Em 13 de julho de 2015, completaram-se 25 anos da publicação do Estatuto da Criança e do Adolescente - ECA (Lei 8.069, de 13 de julho de 1990), quando se discute intensamente a possibilidade de redução da maioridade penal de 18 para 16 anos, trazendo para o debate as questôes voltadas às políticas públicas de proteção à criança, ao adolescente e ao jovem.

É interessante notar que, apesar de termos leis avançadas e bem elaboradas, no mais das vezes o problema que está subjacente não se mostra próximo da solução que se espera.

Regra geral, a explicação está no fato de que as leis, embora publicadas e em pleno vigor, não são efetivamente colocadas em prática e executadas como previsto em seu texto.

Vê-se que, no mais das vezes, a solução dos problemas não está nas leis nem, consequentemente, na sua alteração ou não. Está na sociedade, nas pessoas e, principalmente, na administração pública, que não lhes confere eficácia, e não se tornam reais as prescrições normativas.

Aspectos da maior relevância são relegados a segundo plano, o que compromete as políticas públicas, como é o caso dos aspectos administrativos e financeiros. $\mathrm{O}$ adequado gerenciamento e financiamento das políticas públicas é fundamental para seu sucesso, sendo prioritário dar-lhe total atenção, especialmente neste caso, que é da maior relevância social. Vale refletir sobre o tema para compreendê-lo melhor e qualificar o debate.

A proteção à criança, ao adolescente e ao jovem é política pública que se materializa por um conjunto de ações governamentais e não governamentais que apresenta 
aspectos administrativos bastante complexos, como se poderá ver. Exige sofisticados mecanismos de financiamento e a superação de dificuldades gerenciais.

Complexidade que se constata pela intensa atuação dos poderes e instituições independentes, uma vez que os Poderes Executivo, Legislativo e Judiciário, o Ministério Público, a Defensoria Pública, todos eles exercem funções relevantes voltadas a atingir os objetivos dessa política pública que é prioridade absoluta prevista na Constituição. ${ }^{1}$

Atuam diretamente na própria execução e, principalmente, controle das ações, como se vê pela obrigatória participação do Poder Judiciário e Ministério Público nas medidas de guarda, tutela, adoção, dos atos infracionais, da fiscalização das entidades governamentais e não governamentais de atendimento e tantas outras.

Interferem também para assegurar os muitos direitos fundamentais previstos na Constituição (art. 227) e legislação infraconstitucional ${ }^{2}$ que exigem prestações estatais e têm sido objeto de intensa judicialização visando à concretização ante a inércia estatal, como se pode constatar das várias demandas judicializadas por vagas em creches (STF, RE 436.996-6 Agr e RE 410.715-5 Agr; STJ, REsp 1.185.474), dever de proteção integral (STF, RE 482.611 e STF, RE 488.208) e muitas outras. Uma evidência da distância que existe entre o que está previsto na lei e a realidade.

Mais do que isso, não é simples coordenar todos os entes da federação, em um exemplo claro de federalismo cooperativo que, neste caso, mostra-se bastante evidente, com a participação da União, estados, Distrito Federal e municípios. ${ }^{3}$

Acrescente-se que, ante a sistemática de organização setorial estabelecida na maior parte das administrações públicas, as necessidades das crianças, adolescentes

1 Art. 227: É dever da família, da sociedade e do Estado assegurar à criança, ao adolescente e ao jovem, com absoluta prioridade, o direito à vida, à saúde, à alimentação, à educação, ao lazer, à profissionalização, à cultura, à dignidade, ao respeito, à liberdade e à convivência familiar e comunitária, além de colocá-los a salvo de toda forma de negligência, discriminação, exploração, violência, crueldade e opressão.

2 Dentre outras, o ECA: artigo $7^{\circ}$ - direito à vida e saúde; artigo 53 - direito à educação, à cultura, ao esporte a ao lazer; artigo 60 - direito à profissionalização e à proteção no trabalho, só para citar alguns exemplos; disposições em sentido semelhante estão no Estatuto da Juventude - Lei 12.852, de 5 de agosto de 2013.

3 Veja-se que a cooperação entre entes federados e poderes é intensa, presente em várias situaçôes, como se vê no próprio texto da lei: "Os entes federados, por intermédio dos Poderes Executivo e Judiciário, promoverão conjuntamente a permanente qualificação dos profissionais que atuam diretamente ou indiretamente em programas de acolhimento institucional e destinados à colocação familiar de crianças e adolescentes, incluindo membros do Poder Judiciário, Ministério Público e Conselho Tutelar” (ECA, art. 92, $\$ 3^{\circ}$ ). 
e jovens espalham-se por diversas áreas, tais como saúde, assistência social, educação, segurança pública etc., tornando necessária uma ação conjunta e coordenada de diversos órgãos dentro de uma mesma unidade federativa - sem esquecer que o mesmo ocorre nas demais esferas de governo com as quais os entes federados necessariamente devem de se relacionar.

Não é só. As políticas públicas voltadas para a proteção à criança, ao adolescente e ao jovem estão entre as que mais - e, não seria exagerado dizer, são as que mais - contam com a participação do terceiro setor, por meio da intensa atuação de instituições não governamentais, muitas recebendo subvenções orçamentárias. ${ }^{4}$

Para isso, os recursos, principalmente financeiros, são fundamentais.

Já na Constituição há referências ao aporte de recursos públicos ao setor, diretamente (percentual a ser destinado à saúde na assistência materno-infantil - art. $227, \$ 1^{\circ}, \mathrm{I}$ ), ou por meio de incentivos fiscais (acolhimento e guarda de órfãos e abandonados - art. $227, \$ 3^{\circ}$, VI), e a criação de programas governamentais específicos para atendimento àqueles portadores de deficiência, e também aos dependentes de drogas (art. 227, $\$ 3^{\circ}$, VII).

O ECA, em suas diretrizes, dá ênfase a vários aspectos financeiros, regulando atribuições dos entes federados (art. 88, I), orienta para a criação e manutenção de programas governamentais de forma descentralizada (art. 88, III), e fomenta a manutenção dos fundos nacional, estaduais e municipais (art. 88, IV), principais instrumentos financeiros desta política pública. E chama a atenção para a já mencionada necessidade de integração operacional dos órgãos do Judiciário, Ministério Público, Defensoria, Segurança Pública e Assistência Social (art. 88, V e VI).

No ECA, os principais aspectos financeiros, não obstante sua relevância, vêm tratados nas "disposiçôes finais e transitórias", especialmente no artigo 260, que cuida das doaçôes para os Fundos dos Direitos da Criança e do Adolescente.

Neste ponto, convém destacar serem os Fundos dos Direitos da Criança e do Adolescente os principais instrumentos financeiros voltados a viabilizar e as políticas públicas destinadas ao setor, que devem ser instituídos e cadastrados pelos entes federativos para melhor gerenciar seus recursos - o que, registre-se, ainda não se materializou integralmente. ${ }^{5}$

4 A própria legislação reconhece isso e é expressa ao estabelecer que "a política de atendimento dos direitos da criança e do adolescente far-se-á através de um conjunto articulado de ações governamentais e não governamentais, da União, dos estados, do Distrito Federal e dos municípios" (ECA, art. 86).

5 <http://www.sdh.gov.br/assuntos/criancas-e-adolescentes/cadastramento-de-fundos>. 
O Fundo Nacional para a Criança e Adolescente está previsto no art. $6^{\circ}$ da Lei 8.242, de 1991, que criou o Conanda (Conselho Nacional dos Direitos da Criança e do Adolescente), órgão responsável por geri-lo (art. 2º, X) e que tem várias outras atribuições relevantes em matéria financeira, como a de zelar pela aplicação da política nacional de atendimento dos direitos da criança e do adolescente (art. $2^{\circ}$, I) e acompanhar a elaboração e a execução da proposta orçamentária da União (art. 2o, IX).

Mas não é somente esse o ponto que merece ser destacado no aspecto financeiro e administrativo. $\mathrm{O}$ bom gerenciamento de qualquer política pública parte, inicialmente, de um planejamento bem construído e executado - o que ainda deixa a desejar nessa matéria.

Inicialmente, vê-se que, em âmbito nacional, a proteção à criança, ao adolescente e ao jovem conta com vários planos, nos quais se pode notar falta de coordenação tanto no aspecto temporal, pois abrangem, muitas vezes, períodos diferentes, quanto no próprio conteúdo, com previsões nem sempre coesas entre si. E, no mais das vezes, juridicamente frágeis por sequer estarem aprovados por lei, mas por atos normativos infralegais ou nem isso.

Uma análise do tema permite encontrar o Plano Nacional de Promoção, Proteção e Defesa do Direito de Crianças e Adolescentes à Convivência Familiar e Comunitária, ${ }^{6}$ elaborado por vários órgãos do Poder Executivo Federal e formalizado pela Resolução Conjunta CNAS-Conanda 1/2006, em que se constata que objetivos, ações, resultados, indicadores, prazos e metas não são claros e específicos o suficiente para permitir adequados acompanhamento e controle. Elaborado para o período 2007-2015, é fácil constatar que, faltando seis meses para o final, não será integralmente implementado.

Reparos semelhantes podem ser feitos em outros planos e acrescente-se que, ao analisá-los, evidencia-se o já mencionado caráter multidisciplinar e intersetorial, pois elaborados no âmbito de vários órgãos diferentes da administração pública. Temos o Plano Nacional de Prevenção e Erradicação do Trabalho Infantil e Proteção ao Trabalhador Adolescente, de 2004, elaborado pelo Ministério do Trabalho e Emprego; ${ }^{7}$ o Plano Nacional de Enfrentamento da Violência Sexual contra

6 BRASIL. Conanda/CNAS/SEDH/MDS. Plano Nacional de promoção, proteção e defesa do direito das crianças e adolescentes à convivência familiar e comunitária. Brasília: MDS, 2006.

7 BRASIL. Ministério do Trabalho e Emprego. Plano Nacional de Prevenção e Erradicação do Trabalho Infantil e Proteção ao Trabalhador Adolescente. Prevenção e erradicação do trabalho infantil e proteção ao trabalhador adolescente. Brasília, Ministério do Trabalho e Emprego, Secretaria de Inspeção do Trabalho, 2004. 
Crianças e Adolescentes, de 2013; ${ }^{8}$ a Política Nacional de Educação Infantil - pelo direito das crianças de zero a seis anos à Educação, de 2006, elaborado pelo Ministério da Educação," dentre outros.

No aspecto financeiro, o mais relevante é o Plano Plurianual - PPA, válido para toda a administração pública federal. Está em vigor, até o final do ano, o PPA 2012-2015 (Lei 12.593, de 18 de janeiro de 2012). Uma análise superficial deste PPA permite evidenciar claramente as dificuldades e fragilidades administrativas e financeiras a serem enfrentadas. Nele se constata a já mencionada dificuldade administrativa decorrente da intersetorialidade das políticas públicas voltadas à proteção da criança, do adolescente e do jovem, espalhadas por diversos programas em várias áreas e órgãos da administração pública, que cuidam de temas direta e indiretamente a elas vinculados como educação, cultura, esporte, saúde, segurança, assistência social, trabalho e tantas outras. ${ }^{10}$

Dentre os programas governamentais contemplados no PPA que se voltam mais diretamente ao setor, pode-se destacar o Programa 2.062 - Promoção dos Direitos de Crianças e Adolescentes, com cinco objetivos, desdobrados em 31 metas, ${ }^{11}$ e não é difícil constatar que muito do que está previsto não será cumprido.

Vê-se haver esforços de todas as esferas de governo no sentido de observar a prioridade absoluta que a Constituição atribui aos direitos fundamentais da criança, do adolescente e do jovem, e houve efetivamente grandes avanços. Mesmo assim, há ainda muito a fazer e é longo o caminho a percorrer. Se fossem atingidos todos objetivos e metas que constam dos vários planos e do PPA, muito provavelmente a

8 BRASIL. Conanda e SDH. Plano Nacional de Enfrentamento da Violência Sexual contra Crianças e Adolescentes. Brasília: Conanda-SDH, maio de 2013.

9 BRASIL. Ministério da Educação. Secretaria de Educação Básica. Política Nacional de Educação Infantil pelo direito das crianças de zero a seis anos à educação. Brasília: MEC/SEB, 2006.

10 Isto pode ser bem observado no bom trabalho destinado a apurar o "Orçamento Criança e Adolescente", em que se verificam as dificuldades em se identificar, apurar e calcular os recursos previstos nas leis orçamentárias para a criança e adolescente (Fundação Abrinq; Inesc; Unicef. De olho no orçamento criança. São Paulo, 2005).

11 Entre as quais estão "implantar serviços de atendimento integrado a crianças e adolescentes vítimas de violência sexual nas 27 capitais", "implantar serviços integrados de atendimento inicial a adolescentes em conflito com a lei nas 27 capitais", "equipar 100\% dos Conselhos Tutelares dos 1.000 municípios com menor IDI e IDH, localizados nas regiões Norte e Nordeste, com sede, computador, telefone e meio de transporte", "implantar Escolas de Conselhos nas 27 unidades federadas, com modalidade presencial integrada aos programas de ensino à distância", "universalizar os Conselhos Tutelares, estendendo-os a todos os municípios", "universalizar Conselhos de Direitos da Criança e do Adolescente, estendendo-os a todos os municípios", entre tantas outras. 
situação não estaria tão ruim e os problemas hoje existentes, se não eliminados, seguramente seriam bem menos relevantes e preocupantes, e talvez não fosse necessário cogitar de alterações na legislação. E referidos objetivos e metas integram leis, entre as quais o plano plurianual, razão por que não podem ser considerados apenas promessas, mas compromissos formalmente assumidos e que devem ser cumpridos. As leis de natureza orçamentária, como o PPA, têm conteúdo material e caráter impositivo, não são meras peças de ficção, como já se discutiu neste espaço (Coluna Orçamento não pode mais ser uma peça de ficção, publicada em 2 de junho de 2015).

As prescriçõoes da Constituição, do Estatuto da Criança e Adolescente, dos planos, especialmente de natureza financeira, e as muitas normas aplicáveis a esta política pública ainda não se tornaram realidade. Enquanto isso não ocorrer, não há como se reconhecer serem boas ou ruins, sendo, portanto, pouco relevante preocupar-se em alterá-las. Aumentar ou diminuir a maioridade penal, encarcerar ou internar, com 18 ou 16, 14 ou 20 anos, seguramente trará resultados, ainda que eventualmente positivos, pífios. Mantidas ou modificadas, as normas vigentes precisam, em primeiro lugar, ser cumpridas - e essa é a prioridade. 